\title{
Land Covers and Climate Impacts on Land Surface Temperature in Putrajaya, Malaysia
}

\author{
Siti Aekbal Salleh ${ }^{1}$, Zulkiflee Abd.Latif ${ }^{1}$, \\ Wan Mohd. Naim Wan Mohd ${ }^{2}$, Andy Chan ${ }^{3}$ \\ ${ }^{1}$ Applied Remote Sensing and Geospatial Research Group \\ ${ }^{2}$ Centre of Studies Surveying Science and Geomatics, Faculty of Architecture Planning and \\ Surveying, Universiti Teknologi MARA, 40450 Shah Alam, Selangor. \\ ${ }^{3}$ Faculty of Engineering, \\ University of Nottingham, Campus Semenyih, Jalan Broga, Selangor, Malaysia \\ aekbal@salam.uitm.edu.my
}

\begin{abstract}
This study investigates the influence of surface heterogeneity to the land surface temperature (LST). The land cover changes evaluation and historical climate data comparison were used in this study. Land cover, Normalised Difference Vegetation Index (NDVI), Normalised Difference Built-up Index (NDBI) and LST maps are produced to quantify the impacts of urbanization towards the surface thermal behaviour. The urbanization was set on years 1999 to 2006. While urbanization continued in 2009, the surface temperature was lower than that of 2006. The sea level was notably high during 2006, suggesting the lost of ice extent and evident to the climate change effects. Therefore, the fluctuation of temperature in 1999 to 2009 manifestly influenced by green space and climatic response and not solely caused by urbanization.
\end{abstract}

Keywords: Land surface temperature, Land cover, Urban, Climate.

eISSN 2514-751X @ 2018. The Authors. Published for AMER ABRA cE-Bs by e-International Publishing House, Ltd., UK. This is an open-access article under the CC BY-NC-ND license (http://creativecommons.org/licenses/bync-nd/4.0). Peer-review under responsibility of AMER (Association of Malaysian Environment-Behaviour Researchers), ABRA (Association of Behavioural Researchers on Asians) and CE-Bs (Centre for EnvironmentBehaviour Studies), Faculty of Architecture, Planning \& Surveying, Universiti Teknologi MARA, Malaysia DOI: https://doi.org/10.21834/aje-bs.v3i10.315 


\subsection{Introduction}

Energy and climate are highly associated with the built environment. Built environment is not only comprised of building collections, but also the physical results of various economic, social and environmental processes (Santamouris \& Asimakopoulos, 2001). Urban microclimate change effects can be seen when major cities experience the formation of urban heat islands, due to urban expansion, pollution growth, and the development of major industrial activities in metropolitan areas (Ghazanfari, Naseri, Faridani, Aboutorabi, \& Farid, 2009). Urbanization promotes the changes of Land covers. Human activities are a major influence of urban climate because the concentration effects of their activities may differ considerably from surrounding rural regions. Changes of land cover will relatively change surface properties, for example the heat capacity, heat conductivity, albedo and roughness length (Mölders, 2011), see Figure 1.

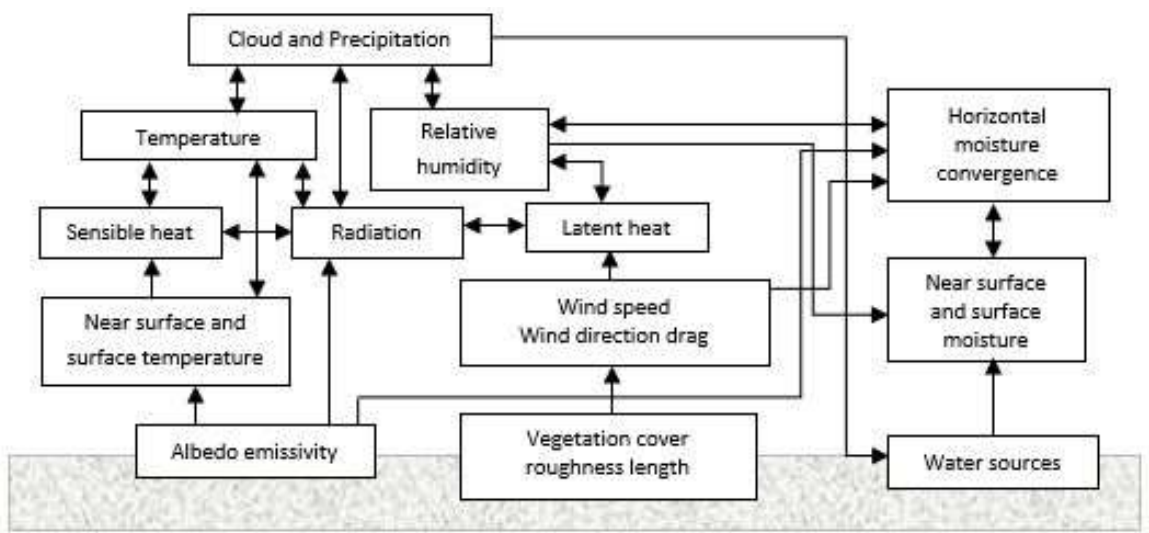

Figure 1: Primary, secondary and biogeophysical response of land cover change (adapted from Mölders, 2011).

Land cover change modifies thermal stratification and evaporation. These will definitely alter the atmospheric boundary layer temperature and moisture. Hence, it impacts the urban climate condition remarkably. Extensive previous studies have explored the causes and factors contributing to the formation of UHls. One ideal resolution, summarized by Voogt \& Oke (2003), included the following:

- Canyon Radiative Geometry - decreased long-wave radiation loss from within street canyons due to the complex exchange between buildings and the screening of the skyline.

- Thermal Properties - increased storage of sensible heat in the fabric of the city.

- Anthropogenic Heat - heat released from combustion of fuels and animal metabolism.

- Urban 'Greenhouse' - increased incoming long-wave radiation from the polluted and warmer urban atmosphere. 
- Canyon Radiative Geometry - multiple reflections of short-wave radiation between the canyon surfaces decreasing the effective albedo of the system.

- Evapotranspiration - reduction of evaporating surfaces in the city, putting more energy into sensible heat and less into latent heat.

- $\quad$ Shelter - reduced turbulent transfer of heat from within streets.

\subsection{Climate Change and Heat Island Effects on Human Health and Mortality.}

Climate change and changes of land use have similar impacts on society health and living. Both changes focus on the deterioration of ecosystem dynamics and its stabilization. Myers \& Bernstein (2011) reported how global climate change may affect human health and nutrition resources. Many studies have outlined the direct impacts of climate change, such as heat stress (Heisler \& Brazel, 2010; Li, Zhou, Ouyang, Xu, \& Zheng, 2012), air pollution (Afroz, Hassan, \& Ibrahim, 2003; Taha \& Sailor, 2010), and the transmission of infectious diseases (Tomlinson, Chapman, Thornes, \& Baker, 2011). Human health is affected by climate change through biogeochemical interactions and the presence of biological responses towards the climate and the atmospheric composition. Arneth et al.(2010) suggested that the biosphere influences, and to a certain degree, regulates atmospheric composition, chemistry, and climate change via biogeochemical feedback processes. Increased temperature can also amplify air pollution concentrations (Gartland, 2012; Roberts, 2004), and thus lead to the formation of major cardio respiratory allergies, such as asthma (Koken et al., 2003). Pollution particles reflect solar radiation, leading to a decrease in solar energy reaching the surface. The mitigation of a heat island improves air quality in the following three different ways (Gartland, 2012):

- A cool environment will provide less demand for energy, and thus, reduce pollution from power plants

- Trees and vegetation help to improve the transportation of air pollutants, such as oxides of sulphur and nitrogen; thus reducing air pollution.

- With cooler air temperatures, the formation of fog is less.

The importance of having urban green campaigns and infrastructures was suggested to influence the urban community's environment (Mansor, 2010). Outdoor participation leads to healthier lifestyles and helps to resolve the adverse effects of climate change, thus transforming the well-being of urban society and its environment. A major mitigation strategy, which has received global recognition and attention, is the escalation of surface cooling properties, which is the land surface albedo (Akbari, Matthews, \& Seto, 2012). Land surface albedo is suggested to have a direct relationship with surface heat (Jiang, Zhang, Gao, \& Miao, 2007).

\subsection{Rationale}

The modifiable factors of climate change, urbanization, and the UHI phenomenon are an indication of the need to investigate whether a warmer city results solely from development 
and modernization; or the effect of each other co-existing. Given the opportunity of having Putrajaya as a planned city; being built according to a series of comprehensive policies and guidelines for land use, the possibility to investigate whether such a well-structured city that holds a concept of greenery and climate adaptation, can still induce UHI. Thus, the magnitude of urbanization amplifies the city's emissions and the heat needs to be measured. Measuring changes in satellite-derived land surface temperatures over time provides a quantitative means in tracking surface change. This information can be used for global and regional climate change and ecosystem applications; particularly those which have to monitor energy transfer at the surface. According to Mustafa (2009) Putrajaya was designed to suit; the topographical conditions, local climate, and cultural norms enriching the local urban form; the creation of an interesting cityscape; the optimization of scenic panoramic views and spatial experiences; the promotion of local flora as a Malaysian landscape identity; the creation of a network of open spaces, and finally; the incorporation of intelligent buildings and infrastructural features. One of Putrajaya's main shortcomings is that climatic response in planning, architecture, and landscape architecture was minimal. Moser (2010) assented that Putrajaya's designers failed to reclaim the use of urban microclimatic features that were developed in the Middle East to contradict the effects intense heat from a constant sun illumination (Hakim, 1994). The green environment that transpires through parks and gardens, only provide limited power in reducing the heat. This is because, its consist of decorative landscape rather than huge canopies or long benches of trees with a very little vegetative cover along the side walk. Perhaps, some of the issues raised by these authors should be taken into account. With all of the above mentioned factors, the Putrajaya area is eminently suitable for conducting this research.

\subsection{Methodology}

The method adopted in this study comprises the basic remote sensing imagery processes for extraction of land surface temperature, producing maps of NDBI and NDVI to measure the built-up index and vegetation's Index which is used to attune the land surface temperatures.

\subsection{Land Surface Temperature (LST) Extraction Technique}

Prior to extracting the LST, the Dark Object Subtraction algorithm was applied by using the COST method (Chavez, 1996) for atmospheric correction. Then, two methods of LST extraction were applied in this study, known as Split Window (Mao et al., 2005) and Mono Window (Qin, Karnieli, \& Berliner, 2001). Typical steps are similar in both methods, except for the final equation. The sequences can be seen in Figure 2.

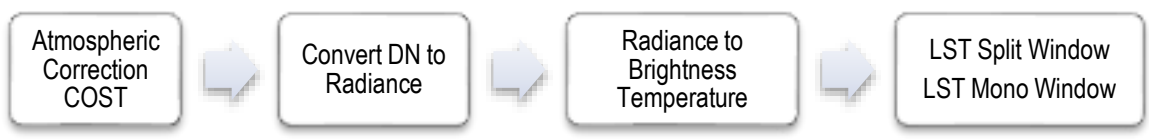

Figure 2: The process in land surface temperature extraction 


\subsection{Measuring Vegetation and Built-up Areas}

Two main equations were used to quantify the values of vegetation and built-up conditions in the study area. These equations are as follows:

i. $\quad$ Normalized Difference Built-up Index (NDBI)

The NDBI enhances the built-up features of the earth's surface. The building and urban area's reflectivity is more concentrated at the middle-infrared (MIR) band compared to nearinfrared (NIR) (Zha, Gao, \& Ni, 2003). Thus, the built-up land can be calculated using this equation:

$$
N D B I=\frac{M I R-N I R}{M I R+N I R}
$$

ii. $\quad$ Normalized Difference Vegetation Index (NDVI)

Based on geometrically corrected Landsat ETM+ images, the NDVI is most commonly used vegetation index. It can be calculated by using this equation:

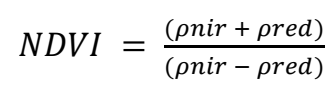

\subsection{Comparison of Land Covers Changes between 1999 and 2009}

The three dates selected for comparison are shown in Figure 3. These dates represent the study area's pre-development, during development, and post development conditions. The temproals analyses of land cover changes, land surface temperatures, Vegetation Index (NDVI), and Built-up Index (NDBI) were conducted and historical climate data were compared (rising sea levels and El Niño-Southern Oscillation (ENSO) incidents).

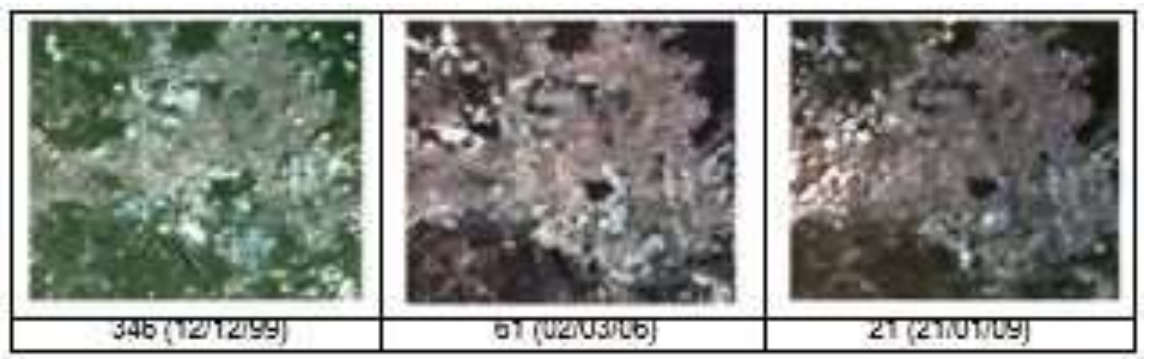

Figure 3: Satellite images used for time series analysis

\subsection{Results and Discussions}

The analyses were divided into two subsections. The first section presents the time series analysis of land covers changes, LST, NDVI, and NDBI. The second section looks at climate 
change reports and documents to verify the existence of climate change influenced to the formation of UHI. Figure 4 shows LST between 1999 and 2009.

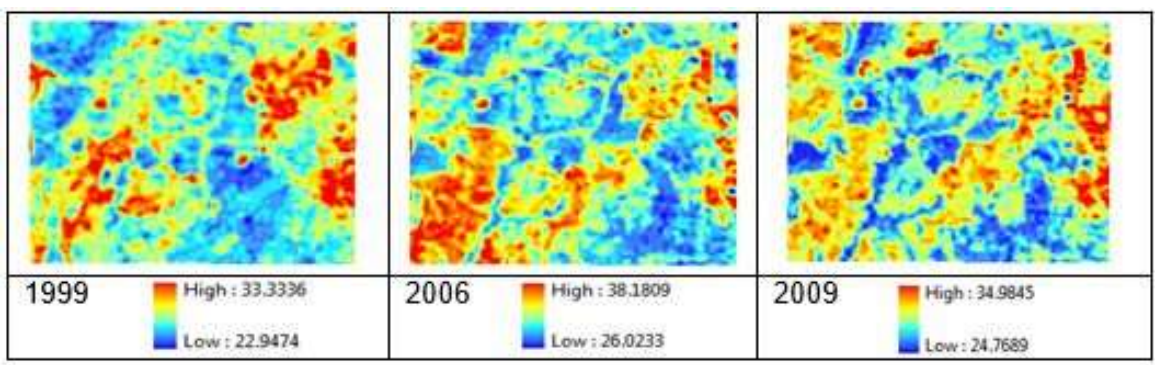

Figure 4: Land surface temperatures between 1999 and 2009

The UHI intensities for 1999, 2006, and 2009 were 5.73, 6.75, and 5.91 degrees Celsius, respectively. The highest intensity (in 2006) shows the multiplication of urbanization activities that amplified the surface temperature of the study area. The declinations in 2009 initiated the need for this study, and at this time, several investigations were conducted.

\subsection{Section 1: Land Covers Changes, LST, NDVI, and NDBI for 1999 to 2009}

Significant increases of urban and developed areas can be visually recognized. This is supported by a remarkable increase of the built-up index of the study area, as well as the reduction of the vegetation index signatures as shown in the NDVI maps. Table 1 explains the percentage changes of five major land covers classes in the study area.

Table 1. Percentage changes of land covers

\begin{tabular}{|c|c|c|c|c|c|c|}
\hline \multirow[b]{2}{*}{ Land Covers } & \multicolumn{2}{|l|}{1999} & \multicolumn{2}{|l|}{2006} & \multicolumn{2}{|l|}{2009} \\
\hline & $\begin{array}{l}\text { Area } \\
\text { (acres) }\end{array}$ & $\%$ & Area (acres) & $\%$ & Area (acres) & $\%$ \\
\hline Water bodies & 274.88 & 1.395 & 408.32 & 2.073 & 259.090 & 1.315 \\
\hline Clear land & 1853.89 & 9.411 & 1505.61 & 7.643 & 966.084 & 4.904 \\
\hline Urban & 8723.00 & 44.282 & 11842.76 & 60.119 & 12699.640 & 64.469 \\
\hline Forest & 4356.28 & 22.114 & 1975.31 & 10.028 & 1007.227 & 5.113 \\
\hline Vegetated/Green & 4490.82 & 22.797 & 3966.86 & 20.138 & 4766.812 & 24.198 \\
\hline
\end{tabular}

Figure 5 illustrates the land cover percentage and area of Putrajaya. The urban areas increased consistently over the years, in agreement with the reduction of forested areas. The green areas in this graph represent vegetation and landscape features, which show an increase of green feature's maturity at three different timeframes. Even though urbanization expanded each year; by $16 \%$ in 2006 and $5 \%$ in 2009, forested areas seemed to be the main casualty as $22 \%$ of these initially forested areas were decreased to just $5 \% .2006$ showed signs of devastation, with a $12 \%$ and $3 \%$ reduction in forested and green areas, Putrajaya managed to recuperate the situation in 2009. The green areas managed to counterbalance 
Salleh, S.A., et.al. / Asian Journal of Environment-Behaviour Studies (ajE-Bs), 3(10) Sep / Oct 2018 (p78-88)

the adverse effects of urban deforestation. Hence, land surface temperatures were at a peak in 2006 , with a maximum temperature of $38^{\circ} \mathrm{C}$, lowering to $34^{\circ} \mathrm{C}$ in 2009 .

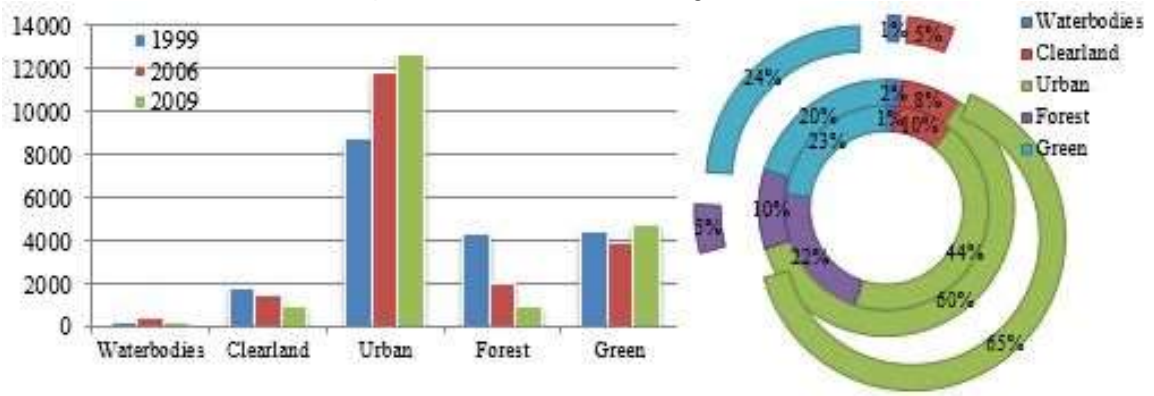

Figure 5: Land covers area (acres) and percentages between 1999 and 2009

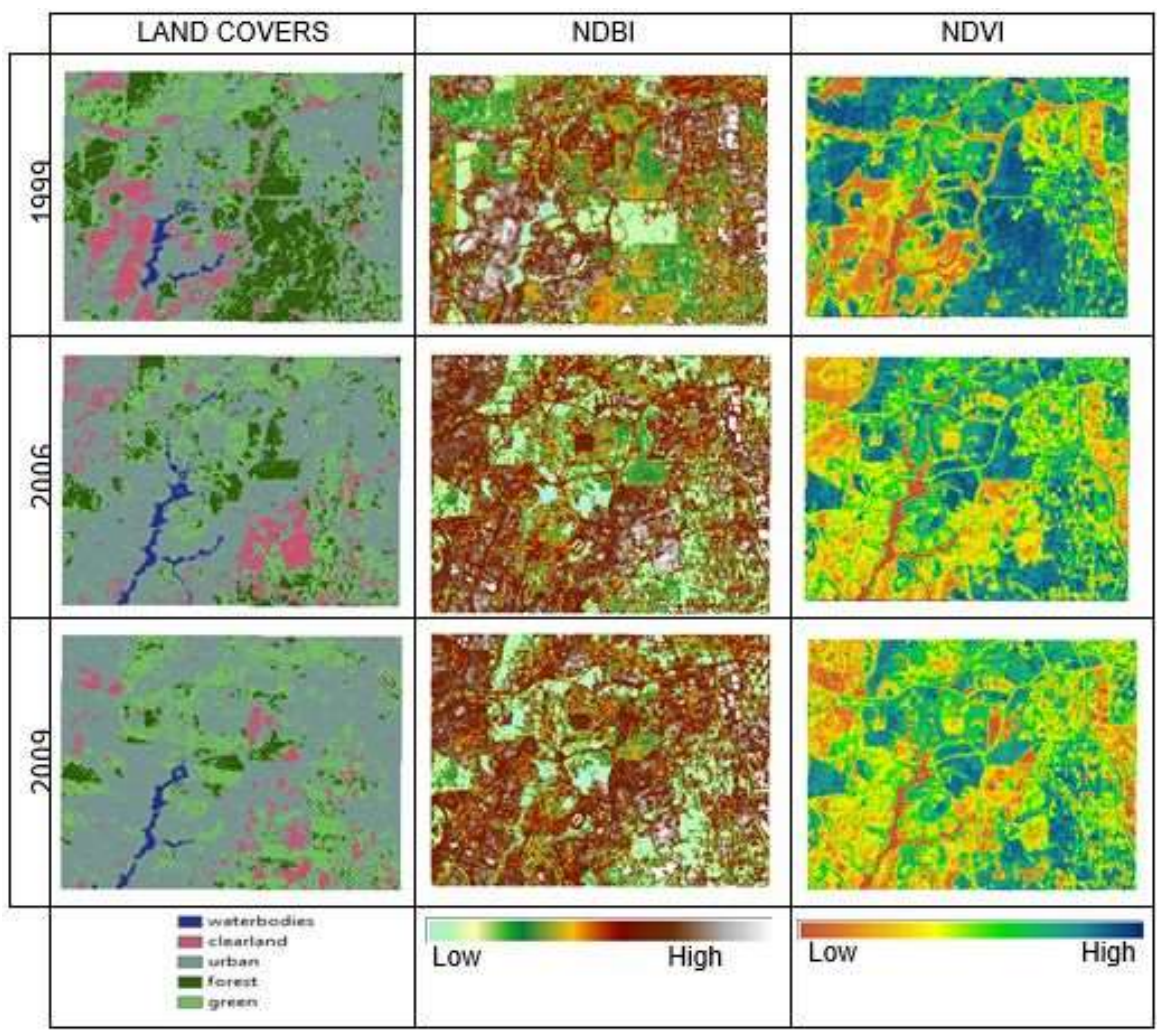

Figure 6: Maps of land cover, NDVI, and NDBI, of the study area 
Aggressive urbanization activities took place between 1999 and 2006; as demonstrated by the percentages of urban and bare land areas being increased, whilst the vegetated and forested areas fluctuated remarkably. Figure 6 shows the land covers maps of the study area, tagged with their NDVI and NDBI maps. Figures 4 and 6 shows that urban areas that include governmental office buildings, commercial, and residential land exhibited the highest temperatures, followed by cleared land and open spaces.

\subsection{Section 2: Climate Change Reports and Events Comparison}

Published reports and papers on climatic events were used to identify the coherence of results in Section 1. The selected dates used for comparison in this study were captured during the North East Monsoon (wet period). However, several climates and monsoons needed to be considered (Indian Ocean Dipole (IOD), El Nino-Southern Oscillation (ENSO), and Madden-Julian Oscillation (MJO)). The IOD brought neutral conditions to the Malaysian region while ENSO led to extreme conditions of wet (La-Nina) and dry (El-Nino). Reports show that two extreme events of ENSO occurred in 1998 (El-Nino) and 1999 (La-Nina). According to global average temperatures recorded between 1850 and 2010 (see Figure 7), the selected timeframe was categorized as the hottest years. This is in line with the results of this study, where the surface temperature ranged from $22^{\circ} \mathrm{C}$ to $38^{\circ} \mathrm{C}$ between 1999 and 2009. Curiously, the 2009 temperature is decreased in spite of the constant growth of urbanization activities and linearly increased temperatures globally. As such, a regional approach case study was looked into. For this instance, another aspect that resulted from global heating (sea level rise and Arctic ice melt) was explored (Gregory \& Oerlemans, 1998).
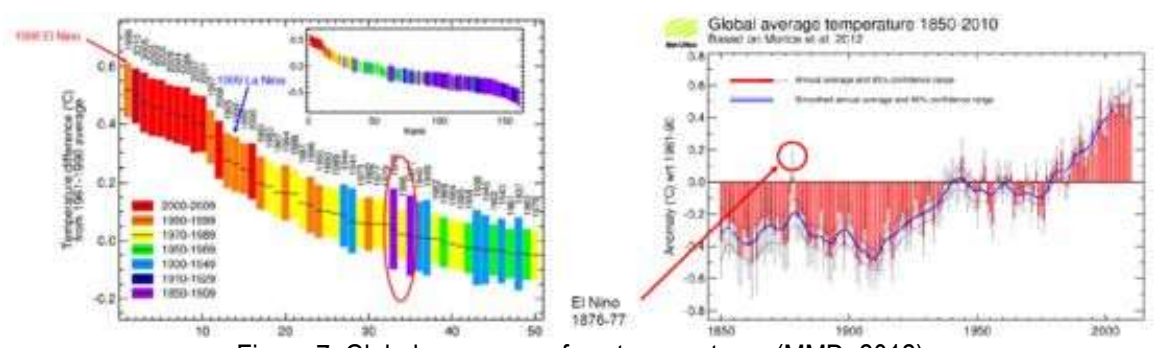

Figure 7: Global average surface temperatures (MMD, 2012)

Sea level has been linked to global temperature. A simulation was performed and showed a strong correlation that explained $98 \%$ of the variance (Vermeer \& Rahmstorf, 2009). The remarkably high sea level in 2006 (NASA, 2013) may have contributed to the increased of surface temperature in that year, the contradict effects can be seen in 2009 where the sea level is lower. This was possibly caused by the late onset of the northeast monsoon, which brought heavy rainfall during mid-Dec 2006. It was also reported that major synoptic features contributed to heavy rainfall episodes during the northeast monsoons of 2006/2007 and 2007/2008 over Malaysia. The late onset of the northeast monsoon in 2007/2008 caused heavy precipitations over Malaysia until the end of 2008 (MMD, 2009). Thus, the declining 
surface temperature shown in Jan 2009 is reasonable. Green space was seen as being valuable in helping to ease the 2009 urban temperature. Through these seasonal and extreme events, the inclining and declining temperature in 2006 and 2009 is evidently influenced by green space and climatic response.

\subsection{Conclusion and Recommendations}

Many have suggested environmental degradations have major links with urbanization. This study reported that a city built with environmental awareness and planning wisdom cannot escape the impacts of climate change. We conclude that climate change strategy for adaptation and mitigation is crucial in educating society to lead a green lifestyle. Mitigating and recuperating the environment need to be enforced at a vast scale to ensure the efforts of having environmental friendly urban areas can be materialized. The proposed climate combat and adaptation strategy framework for urban environments, which involves three phases, is shown in Figure 8.

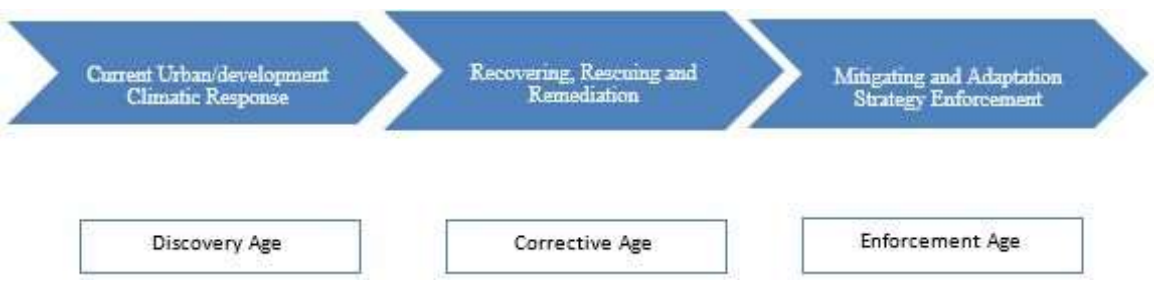

Figure 8: Urban climatic response strategy framework

In this case, it is best to improve and modify what has already been built, rather than totally demolish it. This stage is best referred to as the corrective age. The resolution of Putrajaya Green City 2025 greatly depends on this corrective period; as building and enforcing new green integrated developments can only be complimented if the existing adversity is being rescued and neutralised. The efforts of having green city lifestyle will fall short if climate change effects go riotous without recuperation or rectification. The sustainable planning and management can help to protect the balance of urban biogeophysical and biogeochemical properties while urbanization takes place.

\section{Acknowledgement}

The authors would like to express their gratitude to the Universiti Teknologi MARA (UiTM) and the Ministry of Science, Technology and Innovation (MOSTI) for funding this project under Fundamental Research Grant Scheme (FRGS) (600RMI/SSP/FRGS/5/3Fsp/90/2010), e-Science Fund (06-02-12-SF0131) and also to the Malaysia Meteorological Department and Putrajaya Corporation for sharing their data, 
reports, and documents. The Landsat TM data was available from the U.S. Geological Survey (USGS).

\section{References}

Afroz, R., Hassan, M.N., \& Ibrahim, N.A. (2003). Review of air pollution and health impacts in Malaysia. Environmental research, 92(2), 71-77.

Akbari, H., Matthews, H.D., \& Seto, D. (2012). The long-term effect of increasing the albedo of urban areas. Environmental Research Letters, 7(2), 024004.

Arneth, A., Harrison, S.P., Zaehle, S., Tsigaridis, K., Menon, S., Bartlein, P.J., Feichter, J., Korhola, A., Kulmala, M., \& O'donnell, D. (2010). Terrestrial biogeochemical feedbacks in the climate system. Nature Geoscience, 3(8), 525532.

Chavez, P.S. (1996). Image-based atmospheric corrections-revisited and improved. Photogrammetric Engineering and Remote Sensing, 62(9), 1025-1035.

Gartland, L.M.M. (2012). Heat islands: understanding and mitigating heat in urban areas: Routledge.

Ghazanfari, S., Naseri, M., Faridani, F., Aboutorabi, H., \& Farid, A. (2009). Evaluating the effects of UHI on climate parameters (A case study for Mashhad, Khorrasan). International Journal of Energy and Environment, 3(2), 94-101.

Gregory, J., \& Oerlemans, J. (1998). Simulated future sea-level rise due to glacier melt based on regionally and seasonally resolved temperature changes. Nature, 391(6666), 474-476.

Hakim, B.S. (1994). The" URF" and its Role in Diversifying the Architecture of Traditional Islamic Cities. Journal of architectural and planning research, 11, 108-108.

Heisler, G.M., \& Brazel, A.J. (2010). The urban physical environment: Temperature and urban heat islands. Urban Ecosystem Ecology(urbanecosysteme), 29-56.

Jiang, X., Zhang, C., Gao, H., \& Miao, S. (2007). Impacts of urban albedo change on urban heat island in Beijinga case study. Acta Meteorologica Sinica, 65, 301-307.

Koken, P.J.M., Piver, W.T., Ye, F., Elixhauser, A., Olsen, L.M., \& Portier, C.J. (2003). Temperature, air pollution, and hospitalization for cardiovascular diseases among elderly people in Denver. Environmental Health Perspectives, 111(10), 1312.

Li, X., Zhou, W., Ouyang, Z., Xu, W., \& Zheng, H. (2012). Spatial pattern of greenspace affects land surface temperature: evidence from the heavily urbanized Beijing metropolitan area, China. Landscape Ecology, 27(6), 887898. doi: 10.1007/s10980-012-9731-6

Mao, K., Tang, H., Chen, Z., Qiu, Y., Qin, Z., \& Li, M. (2005). A split-window algorithm for retrieving land-surface temperature from ASTER data. Remote Sensing Information, 7-11.

Mölders, N. (2011). Land-Use and Land-Cover Changes: Impact on Climate and Air Quality (Vol. 44): Springer Verlag.

Moser, S. (2010). Putrajaya: Malaysia's new federal administrative capital. Cities, 27(4), 285-297. doi: http://dx.doi.org/10.1016/j.cities.2009.11.002 
Mustafa, M. (2009). Public Art in the Federal Territory of Putrajaya: Questions of Value and Role. Wacana Seni Journal of Art Discourse, 8.

Myers, S.S., \& Bernstein, A. (2011). The coming health crisis: indirect health effects of global climate change. F1000 Biology Reports, 3.

Qin, Z., Karnieli, A., \& Berliner, P. (2001). A mono-window algorithm for retrieving land surface temperature from Landsat TM data and its application to the Israel-Egypt border region. International Journal of Remote Sensing, 22(18), 3719-3746.

Roberts, S. (2004). Interactions between particulate air pollution and temperature in air pollution mortality time series studies. Environmental research, 96(3), 328-337.

Santamouris, M., \& Asimakopoulos, D.N. (2001). Energy and climate in the urban built environment: Earthscan/James \& James.

Taha, H., \& Sailor, D. (2010). Evaluating the Effects of Radiative Forcing Feedback in Modelling Urban Ozone Air Quality in Portland, Oregon: Two-Way Coupled MM5-CMAQ Numerical Model Simulations. Boundary-Layer Meteorology, 1-15.

Tomlinson, C.J., Chapman, L., Thornes, J.E., \& Baker, C.J. (2011). Including the urban heat island in spatial heat health risk assessment strategies: a case study for Birmingham, UK. International Journal of Health Geographics, 10(1), 42.

Vermeer, M., \& Rahmstorf, S. (2009). Global sea level linked to global temperature. Proceedings of the National Academy of Sciences, 106(51), 21527-21532.

Voogt, J.A., \& Oke, T.R. (2003). Thermal remote sensing of urban climates. Remote Sensing of Environment, 86(3), 370-384

Zha, Y., Gao, J., \& Ni, S. (2003). Use of normalized difference built-up index in automatically mapping urban areas from TM imagery. International Journal of Remote Sensing, 24(3), 583-594. 